\title{
TEACHING NOTE: PROHIBITION FOR THE RELUCTANT LEARNER
}

\author{
Adam Ingano \\ Clinton (MA) High School
}

Teaching American history from primary sources can be challenging. Students often view historical documents with fear and rarely get excited over the prospect of delving into the historical record. Imagine the look on the faces of your students if you were to tell them one of the sources you will be using to study American history is the TV show "The Simpsons." Once students view this assignment as fun or different, you have the chance to teach them something, without them even realizing it. During the long running sitcom's eighth season, an episode entitled "Homer vs. the $18^{\text {th }}$ Amendment" aired. This episode contains numerous historical representations from the Prohibition era of American history. "Homer vs. the $18^{\text {th }}$ Amendment" is not perfect: many historical inaccuracies exist, but it is still good fun with a solid academic payout. Students engage in many higher-order thinking skills through this activity despite the fact that it is "on their level." As a teacher, you have the opportunity to create a highinterest lesson that is not only fun but also possesses a high degree of academic worth. This lesson has been especially effective for me to get reluctant learners to become more engaged in the study of history.

First, let's consider the necessary background knowledge that students will need to manage this assignment. Instructors should cover the $1920 \mathrm{~s}$ in the manner they usually do. A great way to begin the process would be to ask students to research an element or aspect of the time period. Special consideration should be given to (but not restricted to) the following items: $18^{\text {th }}$ Amendment, Eliot Ness, Flappers, W.T.C.U., fashion of the 1920s, Speakeasy, Art of the 1920s, Culture of the 1920s, and "Bathtub Gin." An obvious place to start would be the Women's Christian Temperance Union and the $18^{\text {th }}$ Amendment to the Constitution. Having an understanding of the types of people leading the prohibition movement will be useful in understanding the examples presented on the show. Excerpts from some 1920s novels will give students a feel for the era. Women's fashions, particularly those of the flapper, need to be studied before watching "Homer vs. the $18^{\text {th }}$ Amendment." If students can readily pick out 1920 s era modes of dress, they will notice immediately something unusual in this particular Simpsons episode. Many familiar characters are dressed in a manner befitting the 1920s theme. Knowledge of jazz and the new consumer culture also will help the students pick out some of the more subtle examples. In order to encourage more discussion about these topics, students should complete their background research through a presentation of some sort. This can have benefit if you have students who are usually unwilling to share their knowledge. Once students have learned about some of the selected 1920 s topics, they are ready to apply their knowledge to "Homer vs. the $18^{\text {th }}$ Amendment." 
Certain visual primary source documents also could be considered in your classroom before viewing the episode. Art work from the Ashcan Realist painters of the 1920 s will help students "see" the era. Certainly a closer examination of Edward Hopper's "Nighthawks" painting would ready the class for one particular scene in "Homer vs. the $18^{\text {th }}$ Amendment." At one point the episode shows an image identical to Hopper's "Nighthawks." Prior student knowledge of the painting and a quick touch of the pause button can produce meaningful exchanges about the message Hopper is trying to convey. Any photos or cartoons you can find online or in source books showing the fashion of the 1920 s also will prepare students. A great collection of images entitled "Changing Moral Values: A Visual Essay" that appears in the Enduring Voices: Volume II, a document book to accompany the textbook Enduring Vision, ${ }^{1}$ offers accessible sources. The visual essay contains images created by Art Young, John Held, Jr., and others featured in Collier's, Life, and the New Yorker Magazine. The images, appearing in a book targeted for AP U.S. History students, feature people dressed in styles almost identical to those in "Homer vs. the $18^{\text {th }}$ Amendment." The American Memory website from the Library of Congress offers other great resources for teachers. ${ }^{2}$ Students would benefit from working with images from the Chicago Daily News Negative Collection of prohibition agents destroying illegal liquor and equipment. These sources depict scenes they will see during the episode.

Next, we need to discuss the actual assignment surrounding "Homer vs. the $18^{\text {th }}$ Amendment." The episode will run approximately 23 minutes, shorter than any teaching period. The lesson could be done as an introduction to the $1920 \mathrm{~s}$, but it works better for me as an assessment or an enrichment activity. Students study the 1920s and Prohibition before viewing the episode. Students receive a single question to answer prior to watching and are expected to take notes during. They use their notes, the text, and the notes/discussion on the 1920s topics to answer this single historical question: "Explain the historical accuracy and inaccuracy of the Simpsons" version of Prohibition. Discuss the historical representation of the people, scenes, and themes contained in the episode." Students must be sure that their answer contains both historical information and information from the episode. The final product that students submit is a short research paper based on the episode combined with their own historical interpretations. Once students have watched the show and taken notes, the class can move on to more "normal" means of instruction, with their paper due several days later. All this is done in advance of conventional assessment on the 1920 s.

\footnotetext{
${ }^{1}$ Paul S. Boyer and others, Enduring Vission: A History of the American People (seventh edition, 2011) [13-digit ISBN: 9780495793595$]$.

${ }^{2}$ American Memory, http://www.loc.gov/. Teachers should also consider the primary source analysis tools available from the Library of Congress at http://www.loc.gov/teachers/usingprimarysources/guides. html. Other useful analysis tools, including good lists of questions to ask of primary sources, are available from the National Archives at http://wwww.archives.gov/education/lessons.
} 
In the "Homer vs. the $18^{\text {th }}$ Amendment" assignment, students must apply the information they have learned about the 1920s and analyze the images they have seen. Once they have the necessary background knowledge, they appreciate the TV episode on a different level. Some students pointed out that before studying the 1920 s they never understood this particular episode of "The Simpsons." Several students stated that the project caused them to read and study more of the relevant historical information in order to craft a better paper. One student summed up this view, stating that "I had to get information and make the connections myself, [because] they were not in a textbook or online." These connections, making history relevant to students, are what teaching history should be about, not simply memorization of facts.

Forcing students to apply the historical knowledge they have learned is also forcing them to think like an historian, which is no small feat. Students must think critically about the content and the show rather than simply memorizing facts and recalling them for a test. The discussions that can occur in your class following the episode will cover both content and interpretation of the historical record. Your students might take these ideas even further and surprise you with the content of their papers, citing examples or making historical inferences that even you might have missed. For both students and teachers, setting clear expectations and providing constructive feedback allow the process of learning to continue long after the assignment is completed. 